\title{
Enriched Odor Exposure Increases the Number of Newborn Neurons in the Adult Olfactory Bulb and Improves Odor Memory
}

\author{
Christelle Rochefort, ${ }^{1 *}$ Gilles Gheusi, ${ }^{1,2 *}$ Jean-Didier Vincent, ${ }^{1}$ and Pierre-Marie Lledo ${ }^{1}$ \\ ${ }^{1}$ Perception and Memory Laboratory, Centre National de la Recherche Scientifique Unité de Recherche Associée 2182, \\ Institut Pasteur, 75724 Paris Cedex 15, France, and 'Laboratory of Ethology, Centre National de la Recherche \\ Scientifique Unité de Recherche Associée 7025, Université Paris XIII, 93430 Villetaneuse, France
}

In the mammalian forebrain, most neurons originate from proliferating cells in the ventricular zone lining the lateral ventricles, including a discrete area of the subventricular zone (SVZ). In this region, neurogenesis continues into adulthood. Most of the cells generated in the SVZ are neuronal precursors with progeny that migrate rostrally along a pathway known as the rostral migratory stream before they reach the main olfactory bulb (MOB) where they differentiate into local interneurons. The olfactory system thus provides an attractive model to investigate neuronal production and survival, processes involving interplay between genetic and epigenetic influences. The present study was conducted to investigate whether exposure to an odorenriched environment affects neurogenesis and learning in adult mice. Animals housed in either a standard or an odorenriched environment for $40 \mathrm{~d}$ were injected intraperitoneally with bromodeoxyuridine (BrdU) to detect proliferation among

Although most cells in the nervous system are born during the embryonic and early postnatal period, newborn neurons continue to be generated within at least two areas of the adult mammalian brain (Altman and Das, 1965). The first region concerns the subgranular zone of the dentate gyrus in the hippocampus formation that gives rise to granule cells (for review, see Gage, 2000; Gross, 2000). The second is the subventricular zone (SVZ), which is located in the wall of the lateral ventricle that harbors steadily dividing stem cells and progenitors that produce new neurons (for review, see Peretto et al., 1999; Temple and Alvarez-Buylla, 1999). These neuronal progenitors then migrate by way of the rostral migratory stream (RMS) to populate the main olfactory bulb where they differentiate into local inhibitory interneurons and establish connections with their neuronal targets (Luskin, 1993; Lois and Alvarez-Buylla, 1994).

Bulbar neurogenesis in adulthood implies three distinct processes: (1) cell proliferation, (2) neuroblast migration from the SVZ to the olfactory bulb, and (3) neuronal differentiation and

\footnotetext{
Received Aug. 27, 2001; revised Nov. 29, 2001; accepted Jan. 23, 2002.

This work was funded in part by the Centre National de la Recherche Scientifique, the Ministère de l'Education Nationale, de la Recherche et de la Technologie (ACI Biologie du Développement et Physiologie Intégrative, 2000), and the Institut Universitaire de France. We thank J. Pastre and P. Chevalier for their help with the immunohistochemistry of the hippocampus and water maze experiments. We are also very grateful to J. Morante Oria, A. Saghatelyan, A. Jankovski, and H. McLean for their helpful comments on this manuscript.

*C.R. and G.G. contributed equally to the work.

Correspondence should be addressed to Pierre-Marie Lledo, Institut Pasteur, Perception and Memory Laboratory, 25 Rue Dr. Roux, 75724 Paris Cedex 15, France. E-mail: pmlledo@pasteur.fr.

Copyright (C) 2002 Society for Neuroscience $\quad 0270-6474 / 02 / 222679-11 \$ 15.00 / 0$
}

progenitor cells and to follow their survival in the MOB. The number of BrdU-labeled neurons was not altered $4 \mathrm{hr}$ after a single BrdU injection. In contrast, the number of surviving progenitors 3 weeks after BrdU injection was markedly increased in animals housed in an enriched environment. This effect was specific because enriched odor exposure did not influence hippocampal neurogenesis. Finally, we showed that adult mice housed in odor-enriched cages display improved olfactory memory without a change in spatial learning performance. By maintaining a constitutive turnover of granule cells subjected to modulation by environmental cues, ongoing bulbar neurogenesis could be associated with improved olfactory memory.

Key words: behavior; cell survival; interneurons; hippocampus; olfaction; progenitor cells; neurogenesis

survival. For example, Ephrin molecules were shown to control specifically cell proliferation of neuroblasts in the SVZ (Conover et al., 2000). With respect to migration, the polysialylated form of neural cell-adhesion molecules (PSA-NCAM) has been identified as a key factor in assuring efficient migration of neuroblasts in the RMS (Bonfanti and Theodosis, 1994; Rousselot et al., 1995; Doetsch and Alvarez-Buylla, 1996; Lois et al., 1996; Chazal et al., 2000). Two members from the Slit family of soluble proteins are also good candidates for guiding neuroblasts toward the olfactory bulb (Hu, 1999; Wu et al., 1999).

It has been proposed that target structures are the major sources for providing attractive and survival factors (Kennedy and Tessier-Lavigne, 1995; Svendsen and Sofroniew, 1996). The maturation and survival of SVZ-generated neurons are partly under the control of brain-derived neurotrophic factor (BDNF) (Kirschenbaum and Goldman, 1995). Although the sources of these factors in vivo are not precisely known, olfactory bulbderived factors are likely to influence the proliferation and survival of SVZ neuroblasts in the adult brain. In mice, neural activity may be important in regulating neuroblast proliferation and survival because closure of one nostril affects the dynamics of neuronal birth and death in the corresponding olfactory bulb (Murray and Calof, 1999). However, it was demonstrated recently that SVZ cells continue to divide and migrate after transection of the olfactory peduncle (Jankovski et al., 1998) or after olfactory bulb removal (Kirschenbaum et al., 1999). This suggests that activity within the olfactory bulb is not essential for proliferation or the directional migration of newly generated interneurons. Thus, the role of the bulbar activity for the survival of newborn 


\begin{tabular}{ll}
\hline $\begin{array}{l}\text { Table 1. List of different natural odors used to enrich the olfactory } \\
\text { environment and chemical molecules to challenge olfactory } \\
\text { performances }\end{array}$ \\
Olfactory enrichment & Behavioral test \\
\hline Lavender & M-Xylol \\
Garlic & Octanol \\
Paprika & Vanilla \\
Marjoram & $(+)$-Carvon \\
Curry & $(-)$-Carvon \\
Rosemary & Isoamyl acetate \\
Nutmeg & Caprinaldehyd \\
Thyme & Propionaldehyd \\
Basil leaves & Butyraldehyd \\
Cumin & Valeraldehyd \\
Cardamom & Capronaldehyd \\
Tarragon & Aneth \\
Whole cloves & Massale \\
Chocolate & Paprika \\
Celery & Mint \\
Anise & Coffee \\
Ginger & Nutmeg \\
Lemon & Curry \\
Orange & Rosemary \\
Banana & Cinnamon \\
\end{tabular}

neurons arriving in the main olfactory bulb remains to be clearly established.

It is widely accepted that the adult brain can respond to environmental and internal challenges inducing significant functional and anatomical modifications, collectively termed "neural plasticity." This has been well documented for the perinatal period called "critical period," in which sensory-driven activity patterns are able to induce long-term changes in specific neuronal circuits lasting throughout adulthood (Berardi et al., 2000). Interestingly, recent analyses of this plasticity indicate that a developmental mismatch between inhibition and excitation could provide a time frame during which the reorganization of cortical circuitry can be particularly influenced by sensory experience (Huang et al., 1999; Fagiolini and Hensch, 2000). The self-renewing capacity of the olfactory bulb inhibitory neuronal network leaves open the possibility that the critical period may never end in the olfactory system. In fact, odor experiences have been reported to modulate adult olfactory bulb functions (Rabin, 1988; Rosselli-Austin and Williams, 1990; Woo and Leon, 1995). If activity-dependent recruitment of neurons is related to odor stimulation, the question, then, is whether a change in the number of newborn interneurons might be related to changes in olfactory behavioral function. Using a combination of immunohistological and behavioral approaches, we show that an odor-enriched environment enhances the bulbar interneuron population and improves olfactory memory without upregulating hippocampal neurogenesis.

\section{MATERIALS AND METHODS}

\section{Housing conditions and animals}

Male C57BL/6J mice (2 months old) used for this study were obtained from Janvier (Le Genest St. Isle, France). On their arrival in the laboratory, mice were held in standard laboratory cages $(43 \times 15 \times 28$ $\mathrm{cm}$ ) in groups of 10 , with wood shavings for bedding. They were randomly assigned to two experimental groups. The enriched group $(n=$ 31) consisted of animals housed in an odor-exposure environment for 20 or $40 \mathrm{~d}$. Common odoriferous items were used to enrich the olfactory environment of animals (Table 1). Odor-enriched mice were exposed daily for $24 \mathrm{hr}$ to different aromatic fragrances that were placed in a tea ball hanging from the acrylic filtering cover of standard breeding cages. Standard mice $(n=34)$ were reared under the same conditions except that the tea ball was left empty. Three days before the behavioral experiments, mice were housed singly in polycarbonate cages $(32 \times 14 \times$ $20 \mathrm{~cm}$ ) and familiarized with the test procedure (see below). All behavioral experiments took place in the home cage of the test animals during the dark phase of the day-night cycle under a red light.

Animals were allowed access to food and tap water ad libitum and were kept on a reversed $12 \mathrm{hr}$ light/dark cycle with lights off from 8 A.M. to 8 P.M., with constant temperature. Throughout all experiments, observers were blind to the rearing conditions. All the experiments were performed according to the principles of laboratory animal care published by the French Ethical Committee, and every attempt was made to minimize the number of killed animals.

\section{BrdU labeling and detection}

To determine the quantity of newly generated cells, 5-bromo-2'deoxyuridine (BrdU; at $15 \mathrm{mg} / \mathrm{ml}$; Sigma, St. Louis, MO), a marker of cell proliferation, was administered intraperitoneally $(50 \mu \mathrm{g} / \mathrm{g}$ of body weight dissolved in $0.4 \mathrm{~N} \mathrm{NaOH}$ with $0.9 \% \mathrm{NaCl}$ ). Detection of the labeled progeny cells was done immunohistologically after two different survival times. After a $20 \mathrm{~d}$ period of enrichment, a single dose of BrdU was given $4 \mathrm{hr}$ before killing the animal (to assess proliferation, see Fig. $4 a$ ), or four injections repeated every $2 \mathrm{hr}$ were administrated to animals before they were replaced in their respective cages for 20 more days (to assess neurogenesis, which includes proliferation, migration, and survival; see Fig. 1a).

\section{Immunohistochemistry}

After odor enrichment, mice were given an overdose of sodium pentobarbital (100 mg/kg; Sanofi, France) and perfused transcardially with 50 $\mathrm{ml}$ of saline $(\mathrm{NaCl} 0.9 \%)$ containing heparin $\left(5 \times 10^{3} \mathrm{U} / \mathrm{ml}\right)$ at $37^{\circ} \mathrm{C}$ followed by $200 \mathrm{ml}$ of $4 \%$ paraformaldehyde in $0.1 \mathrm{M}$ phosphate buffer, $\mathrm{pH}$ 7.3. The brain was excised and immersed overnight in the same fixative at $4^{\circ} \mathrm{C}$. Coronal sections were serially cut using a vibrating microtome (Leica) and collected in PBS $(0.1 \mathrm{M}), \mathrm{pH}$ 7.3. BrdU staining was performed on free-floating $40 \mu \mathrm{m}$ sections that were pretreated by DNA denaturation $(2 \mathrm{~N} \mathrm{HCl}$ for $30 \mathrm{~min}$ at room temperature). The primary antibodies used were rat monoclonal anti-BrdU antibody (1:200; Accurate Scientific, Harlan Sera-Lab, Loughborough, UK) and mouse monoclonal anti-NeuN antibody (1:200; Chemicon, Temecula, CA). To determine the number of BrdU-positive cells, staining for BrdU with the peroxidase method was used (ABC system) with biotinylated donkey anti-rat IgG antibodies (1:200) and diaminobenzidine $(0.05 \%)$ as chromogen (Vector Laboratories, Burlingame, CA). The double-labeled immunofluorescence was performed with the following fluorescent secondary antibodies: Alexa 568-labeled goat anti-rat IgG antibody and Alexa 488-labeled goat anti-mouse IgG antibody (both at 1:500) from Molecular Probes (Eugene, OR). Cell-specific markers were used to phenotype the newly born neurons after longer survival times. For this purpose, $\sim 12$ BrdU-positive cells in each of eight randomly chosen sections of the olfactory bulbs were examined for each animal $(n=5$ in standard and enriched groups), and counting is expressed in percentage. Sections were analyzed using either a standard microscope (Leica) for the peroxidase method or a Zeiss confocal microscope with its complementary software package for double labeling.

\section{Image analysis and quantification}

The Spot camera and its accompanying software (Sterling Heights, MI) were used to determine the two- or three-dimensional numerical density of BrdU-immunoreactive (IR) cells, either by selecting predetermined areas to assess proliferation or by analyzing the entire structure to assess neurogenesis in the main olfactory bulb and in the hippocampus.

Olfactory bulb. Immunostained nuclei visualized through a $20 \times$ objective (Leica) were numbered in a one-in-three section, $120 \mu \mathrm{m}$ apart. The granule cell area includes the mitral cell layer, internal plexiform layer, and granule cell layer. The number of BrdU-labeled cells per section was then related to granule cell layer sectional volume to express a density per millimeter cubed.

Lateral ventricle and RMS. As depicted in Figure $4 c$, determined areas $(50 \times 50 \mu \mathrm{m})$ were analyzed on every third section (40 $\mu \mathrm{m}$ thickness). All BrdU-positive nuclei in these selected areas, visualized through a 
$40 \times$ objective, were counted and presented as the number of cells per millimeter squared (see Fig. 4).

Dentate gyrus. To assess survival of newly generated cells in the dentate gyrus of the hippocampus, BrdU-positive cells were numbered in a one-in-two series of sections ( $80 \mu \mathrm{m}$ apart) through a $40 \times$ objective (Olympus) between the stereotaxic coordinates bregma -1.40 and -2.88 $\mathrm{mm}$. The area and the volume of the dentate gyrus were determined $(20 \times$ magnification) in a one-in-two series of sections counterstained with cresyl violet. The number of BrdU-labeled cells was then related to granule cell layer sectional volume to have the density per millimeter cubed.

\section{Olfactory memory and specificity}

Odors were presented by placing $6 \mu \mathrm{l}$ of the odor stimulus onto a $6 \mathrm{~mm}$ circle of filter paper (Whatman \#1). The filter paper was put into a glass Pasteur pipette. This pipette was then introduced through the center of one side of the mesh top, so that the filter paper was $\sim 8 \mathrm{~cm}$ from the floor. This procedure allowed the observer to change the odor stimulus without disturbing the animal. All odors were dissolved in mineral oil $\left(10^{-3}\right)$ and freshly prepared before each experiment.

Three days before tests were run, animals in their home cage were exposed to odor stimuli different from those used in the test session to familiarize them with the procedure. A test session consisted of two 5 min odor presentations of the same odor with a $30,120,180,240$, or 480 min interval. These different intervals were tested randomly in separate sessions spaced at least $24 \mathrm{hr}$ apart. Different odors were used in each test and counterbalanced across the different delay conditions (Table 1). We recorded the time that the animals spent rearing and sniffing at the filter paper. A significant decrease in investigation time during the second presentation indicates that mice were able to recognize an odor that had been presented previously. To assess the specificity of odor recognition, the same animals in a separate experiment were presented with a first odor, followed $30,120,180$, or $240 \mathrm{~min}$ later by exposure to a different one.

\section{Retroactive interference}

Newly stored information may affect retrieval of memories acquired earlier in time. This principle was used in a second series of experiments aimed to examine the consequences of an enriched olfactory environment on the ability of mice to retain the memory of an odor stimulus immediately followed by the presentation of a different odor. To assess the possibility of impairing odor recognition, enriched and standard mice were presented with a second odor (odor 2) 5 min after having been exposed to the first one (odor 1). This was followed by a second presentation of odor 1, $30 \mathrm{~min}$ after it first presentation. Each presentation lasted $5 \mathrm{~min}$, and odors were presented as described previously. The total amount of time investigating the source of odor was recorded during each presentation, as in the previous experiment. A significant decrease in investigation time during the second presentation of odor 1 indicates that test animals were able to recognize this odor despite the presentation of odor 2 .

\section{Water maze}

Twenty-one adult male mice in each group were used in this experiment. Animals were housed in groups of two to three per cage immediately after the end of the $40 \mathrm{~d}$ period. The animals were tested in a circular tank (140 cm diameter) filled to a depth of $40 \mathrm{~cm}$ with white-colored water at $23 \pm 2{ }^{\circ} \mathrm{C}$. The escape platform $(12 \mathrm{~cm}$ diameter $)$ was submerged $1 \mathrm{~cm}$ below the surface of the water. The pool was located in a room with multiple cues on all sides. Each mouse was tested during four daily trials on 4 successive days. The position of the platform was kept constant during training. During the four trials, each mouse was started once from three start positions and allowed to search for the platform. The order of start positions was randomized. The trial ended either when the animal climbed onto the platform or when a maximum of $90 \mathrm{sec}$ elapsed. After the animal found the platform, it was allowed to rest on it for $30 \mathrm{sec}$. If the mouse had not found the platform at the end of the trial, it was gently led to it and allowed to rest for $30 \mathrm{sec}$. The time taken to escape onto the submerged platform (escape latency) was recorded to assess performance.

A probe test was administered after the training trials on day 5. During this test the platform was removed from the pool. Each animal was started in a position opposite the location of the training platform position and allowed to swim for $90 \mathrm{sec}$. The time spent by the animal in the different quadrants was recorded.

\section{Statistics}

Anatomical data were compared between the two groups using Student's $t$ tests for each position of the sections. Behavioral data were analyzed by ANOVA with repeated measures. Olfactory memory analysis included a between group factor (standard versus odor enriched) and two within factors (intervals and exposures). For water maze learning and probe test analyses, the within factor was "days" and "quadrants," respectively. Levels of significance were set at 0.05 .

\section{RESULTS}

\section{Enriched odor exposure and survival of BrdU-labeled cells}

After a daily exposure to different odors and 3 weeks after BrdU injection, most BrdU-labeled cells were found scattered throughout the granule cell layer of the olfactory bulb (Fig. 1c,e). A few cells were also found in the external plexiform and the periglomerular layers (Fig. 1d,f) and occasionally in the mitral cell layer (data not shown). To quantify this neurogenesis, an observer blind to the conditions counted the labeled profiles from both groups. The mean number of BrdU-labeled cells per millimeters cubed found in the main olfactory bulb was significantly higher in the enriched group than in the standard one $\left(t_{8}=2.94 ; p<0.05\right)$ (Fig. $1 g, h)$. An analysis of simple comparisons confirmed that differences between standard and enriched groups were highly significant in the anterior part of the rostrocaudal axis from section 15 to section 39 (respectively: $t_{6}=3.29, p<0.05 ; t_{7}=$ $2.55, p<0.05 ; t_{7}=3.89, p<0.01 ; t_{7}=2.65, p<0.05 ; t_{7}=3.36$, $p<0.01 ; \mathrm{t}_{7}=3.10, p<0.05 ; \mathrm{t}_{8}=4.29, p<0.01$ ) (Fig. $1 g$ ).

Differentiation of newly generated cells was examined in the main olfactory bulb by double labeling for BrdU and a neuronal marker, NeuN (Mullen et al., 1992). We used confocal microscopy to count the number of double- or single-labeled BrdU-positive cells present in enriched and standard olfactory bulbs (Fig. 2). In all cases, cell counts revealed that BrdU-labeled cells were mostly NeuN positive (Fig. $2 a, b$ ). Cells labeled with BrdU but not NeuN (Fig. $2 c, d$ ) are likely to be either glial cells or neurons that have not yet begun to express NeuN. Interestingly, the percentage of BrdUlabeled cells that expressed the neuronal-specific marker did not differ between enriched and standard groups (respectively: $85.8 \pm$ $2.7 \%$ and $81.6 \pm 3.2 \% ; t_{8}=-1.01 ; p>0.05$ ) (Fig. $2 e$ ). From these results, we inferred that the enhanced number of BrdU-positive cells seen in Figure $1 h$ resulted from an increase in the newborn neurons in the experimental bulbs. This finding may result from increased cell proliferation, survival, or both.

\section{Enriched olfactory environment does not affect cell proliferation}

Four hours after a single BrdU injection, animals were killed to assess the proliferation of the progenitors (see Fig. 4a). Cell counts were performed along the entire rostrocaudal axis of the lateral ventricles including the RMS (Fig. 3a,e), the anterior (Figs. $3 b, c, f, g$ ), and the posterior parts of the lateral ventricles (Figs. $3 d, h)$. The rates of cell proliferation were quantified by counting the profile number of BrdU-labeled nuclei within the four rostrocaudal regions of the SVZ (see delimitation of zones in Fig. 4b). No significant difference was found between the odor-enriched $(n=4)$ and standard groups $(n=5)$ in all of the regions that immediately surround the lateral ventricles when expressed as density (respectively: zone $1, t_{7}=-0.76, p>0.05$; zone $2, t_{7}=$ $1.58, p>0.05$; zone $3, t_{7}=0.06, p>0.05$; zone $4, t_{7}=0.78, p>$ 0.05 ) (Fig. $4 d$ ). Because a difference could appear in others region of the SVZ, cells counts were also performed on the entire section. Similarly, no difference between standard and odor- 
a
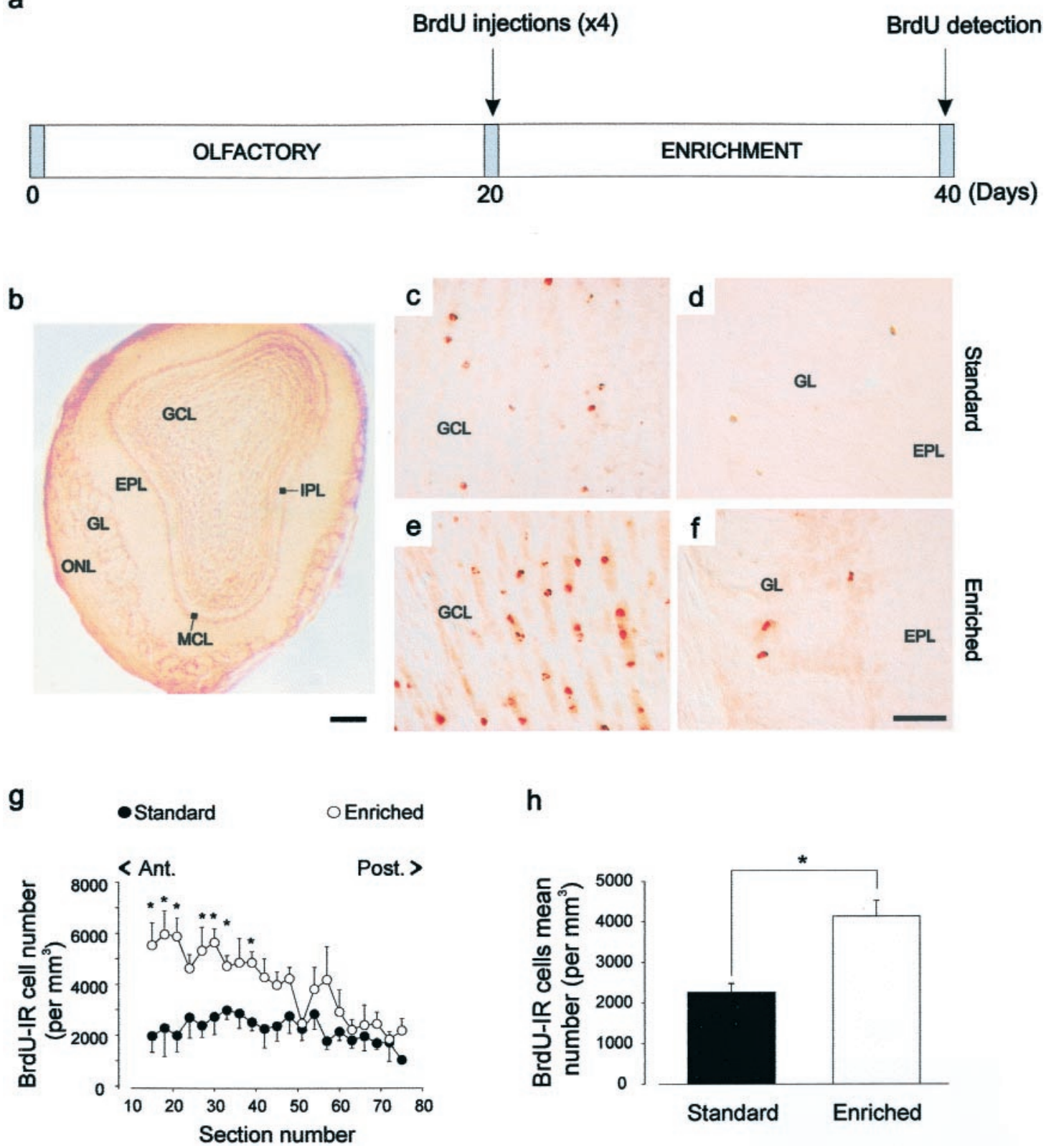

h

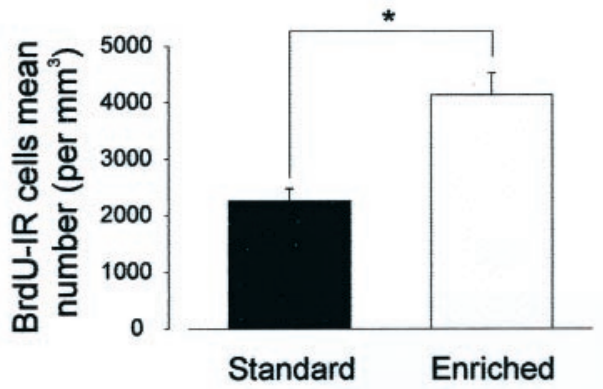

Figure 1. BrdU-positive cell number is increased in the main olfactory bulb from adult enriched mice. $a$, BrdU-labeling protocol. The quantification of neurogenesis (survival of BrdU-labeled cells) was done by counting BrdU-labeled cells at $20 \mathrm{~d}$ after BrdU injection. All animals received four injections of $\mathrm{BrdU}$ at $20 \mathrm{~d}$ after being assigned to the two experimental groups (day 0 ). $b$, Photomicrograph of a coronal section of the main olfactory bulb displaying the different layers. $c-f$, BrdU-IR cells in the GCL $(c, e)$ and in the GL $(d, f)$ of standard $(c, d)$ and enriched $(e, f)$ mice. $g$, Total number of BrdU-IR cells per millimeters cubed throughout the rostrocaudal axis of the olfactory bulb ( $n=5$ for both groups) 3 weeks after injection. $h$, Mean number of BrdU-IR cells per millimeters cubed. * $p<0.05$ with a Student's $t$ test. Scale bars: $b, 300 \mu \mathrm{m} ; c-f, 20 \mu \mathrm{m}$. $O N L$, Olfactory nerve layer; $G L$, glomerular layer; $E P L$, external plexiform layer; $M C L$, mitral cell layer; $I P L$, internal plexiform layer; $G C L$, granule cell layer.

enriched groups could be reported (respectively: zone $1, t_{6}=$ $-0.93, p>0.05$; zone $2, t_{7}=1.05, p>0.05$; zone $3, t_{7}=0.05, p>$ 0.05 ; zone $\left.4, t_{7}=-0.05, p>0.05\right)$. This result demonstrates that enriched olfactory conditions have no influence on the proliferative activity of progenitor cells in the SVZ.

\section{Behavioral olfactory responses}

To examine whether the addition of newborn neurons resulting from environmental enrichment had functional consequences on olfactory behavioral performance, mice were tested in two odor memory tasks. A dramatic improvement of short-term memory was found in mice exposed to the enriched environment (Fig. 5).
A two-way ANOVA with repeated measures (five intervals $\times$ two exposures) on the duration of odor investigation by control and enriched animals revealed in both groups a significant effect of the exposure factor (standards, $F_{(1,15)}=7.47, p<0.05$; enriched, $\left.F_{(1,14)}=50.22, p<0.001\right)$ and its interaction with the interval factor (standards, $F_{(4,60)}=4.71, p<0.01$; enriched, $F_{(4,56)}=4.30$, $p<0.01$ ) (Fig. 5a1,b1). Mice reared in standard conditions showed less interest in investigating the odor during the second exposure at $30 \min \left(t_{19}=5.00, p<0.001\right)$, but not 120, 180, 240, or $480 \mathrm{~min}$ after the first exposure (respectively: $t_{18}=1.95, p>$ $0.05 ; t_{19}=1.96, p>0.05 ; t_{16}=1.38, p>0.05 ; t_{19}=-1.10, p>$ 


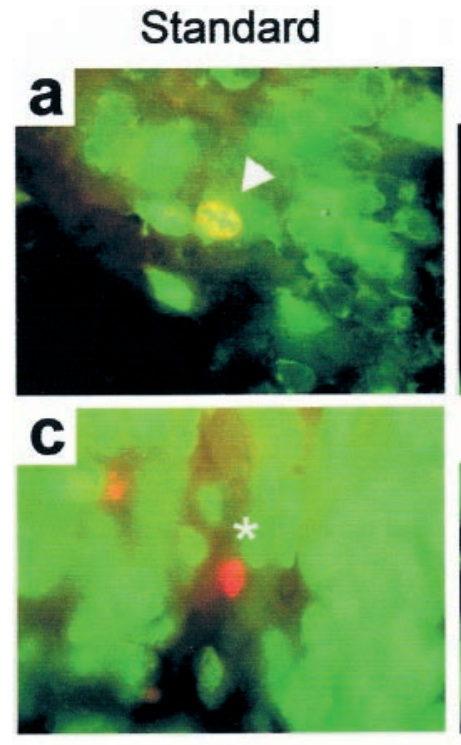

Enriched
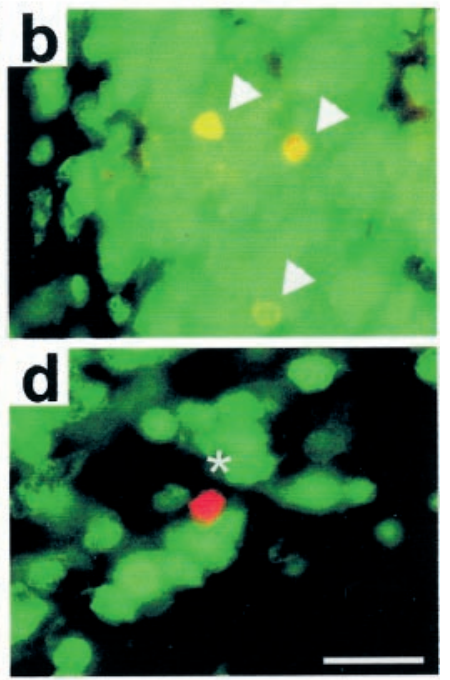

e

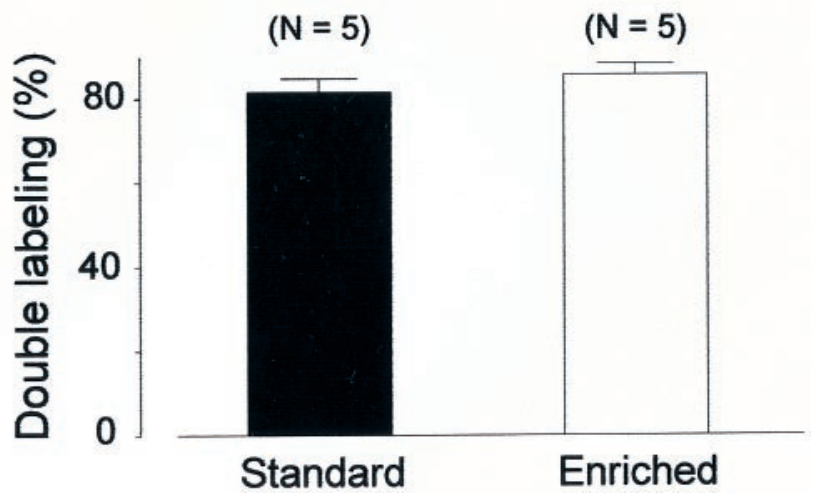

Figure 2. Immunofluorescent identification of newborn cells in the main olfactory bulb. $a-b$, Double-labeled cells (yellow indicated by arrowheads) show the colocalization of BrdU with the neuronal marker NeuN. $c-d$, Some newly born cells are NeuN negative (asterisk). $e$, Percentage of double-labeling cells in enriched and standard mice. Scale bar, $15 \mu \mathrm{m}$.

0.05) (Fig. 5a1). Thus, control mice are able to retain a trace for a period of time shorter than $120 \mathrm{~min}$ as reported previously (Bluthé et al., 1993). In contrast, mice reared in an odor-enriched environment showed a significant reduction in investigation duration when tested after $30,120,180$, and $240 \mathrm{~min}$ (respectively: $t_{17}=5.06, p<0.001 ; t_{17}=4.33, p<0.01 ; t_{17}=4.53, p<0.001 ;$ $t_{16}=5.88, p<0.001$ ) (Fig. 5b1). No significant change in olfactory investigation occurred when the same odor was presented 480 min after its initial presentation $\left(t_{15}=-0.24 ; p>0.05\right)$. These results indicate that in mice, odor memory holds approximately four times longer after enrichment compared with standard conditions.

To ensure that the decrease in investigation time observed at different time intervals is specific to familiar odors and reflects odor memory rather than nonspecific processes (i.e., olfactory satiation), the specificity of odor recognition was assessed. Mice of both groups were presented with an odor, followed 30, 120, 180, and 240 min later by exposure to a different odor (Fig. 6). The results showed that for both groups and for all time intervals tested, there were no significant effects of interval and exposure factors (standards, $F_{(3,51)}=1.22, p>0.05$ and $F_{(1,17)}=1.39, p>$ 0.05 ; enriched, $F_{(3,45)}=1.51, p>0.05$ and $F_{(1,15)}=2.99, p>$
Standard

\section{Enriched}

a

e

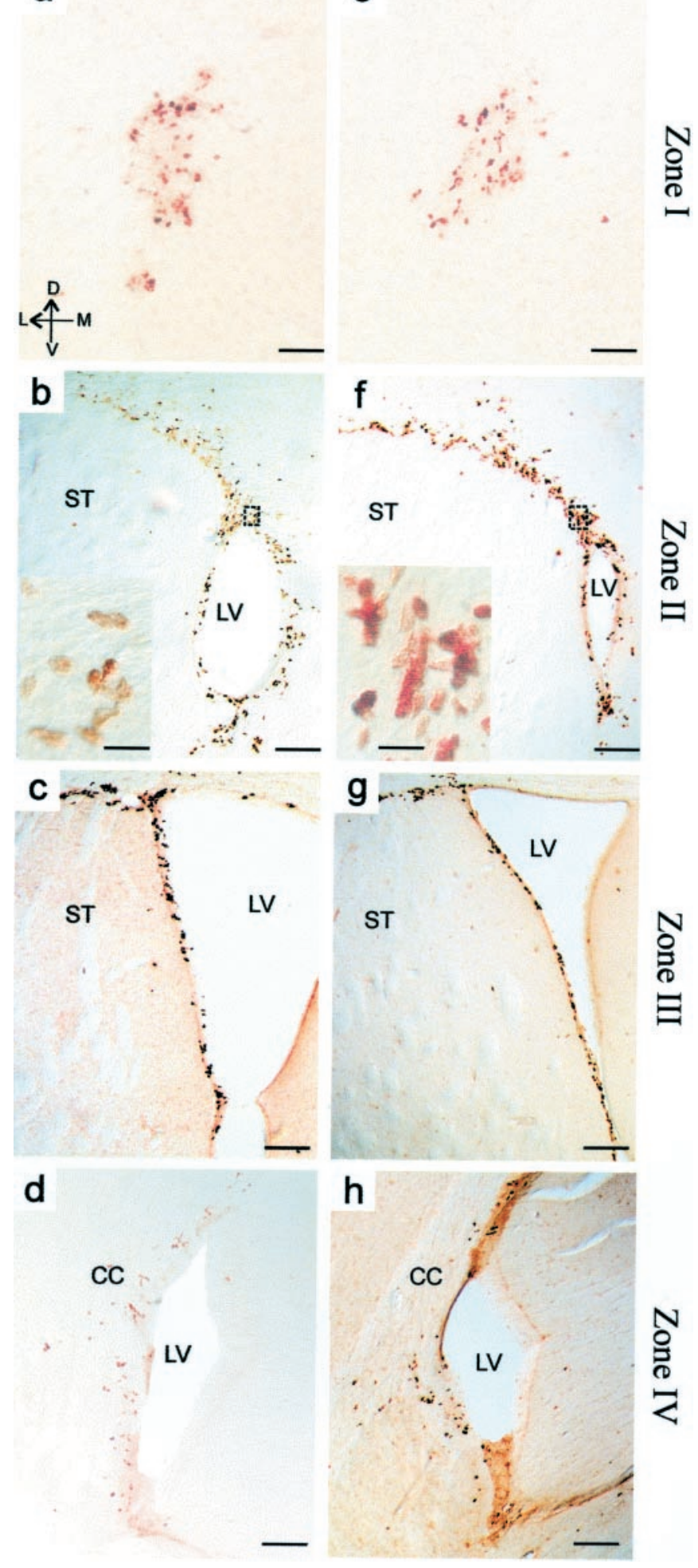

Figure 3. Light micrographs of BrdU-IR cells taken from serial frontal forebrain sections through the RMS $(a, e)$ and in the SVZ of the lateral ventricle $(b-d, f-h)$ from standard (left panels) and enriched (right panels) mice. To assess proliferation, animals received a single systemic intraperitoneal injection of BrdU $4 \mathrm{hr}$ before they were killed. Scale bars: $a, e, 50$ $\mu \mathrm{m} ; b-d, f-h, 300 \mu \mathrm{m}$; insets in $b$ and $f, 20 \mu \mathrm{m}$. $C C$, Corpus callosum; $L V$, lateral ventricle; $S T$, striatum (see Fig. 4 for a delimitation of the four zones). 
a

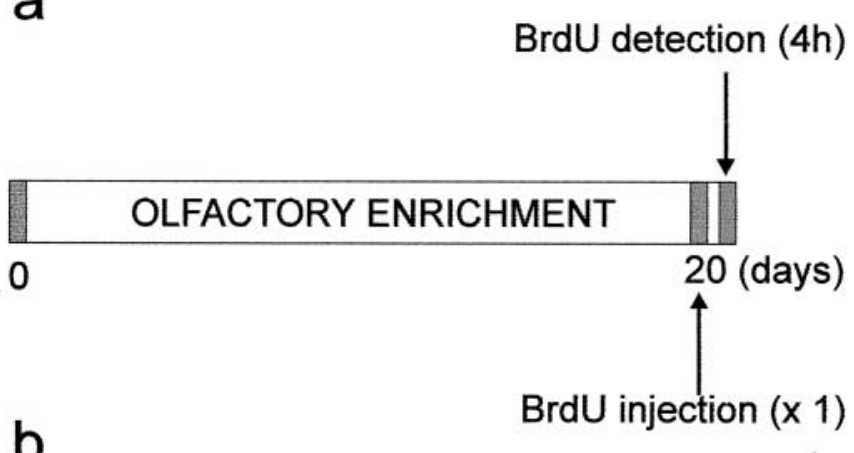

b

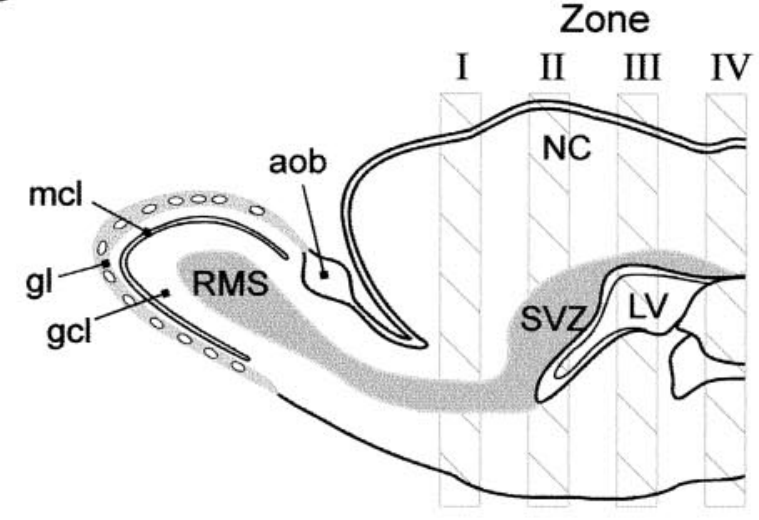

C
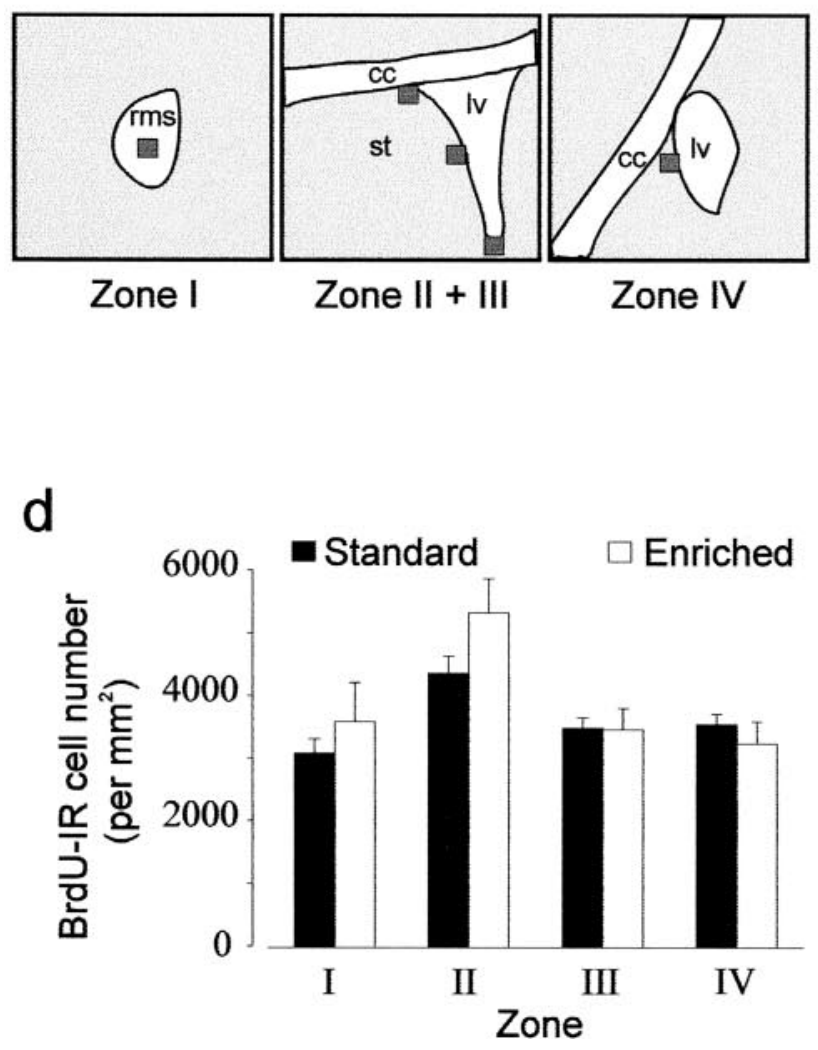

Figure 4. Quantification of proliferation by counting BrdU-labeled cells in enriched $(n=4)$ and standard $(n=5)$ mice throughout the rostrocaudal axis extending from the RMS to the caudal part of the lateral ventricle. $a$, Protocol used to study the proliferation of adult-generated cells labeled with BrdU. A unique intraperitoneal BrdU injection was
$0.05)$ or of their interaction (standards, $F_{(3,51)}=0.93, p>0.05$; enriched, $F_{(3,45)}=0.72, p>0.05$ ) (Fig. 6a1,b1).

Finally, we tested the ability to recognize an odor (odor 1 ) that was followed by a different interfering odor (odor 2) after the first presentation (Fig. 7). Odor 1 was presented $30 \mathrm{~min}$ after its initial presentation, at a time when both groups of mice recognize a familiar odor. A two-way ANOVA (two rearing conditions $\times$ two exposures) on investigation time of the odor revealed no significant effect of rearing conditions $\left(F_{(1,26)}=0.37 ; p>0.05\right)$ but a significant effect of the exposure factor (exposure, $F_{(1,26)}=17.21$; $p<0.001)$ and an interaction between rearing conditions and exposures $\left(F_{(1,26)}=4.30 ; p<0.05\right)$. When standard mice were presented with odor $2,5 \mathrm{~min}$ after the first inspection of odor 1 , the investigation time for the second presentation of odor $1 \mathrm{did}$ not significantly differ from the initial presentation $\left(t_{13}=1.5 ; p>\right.$ 0.05) (Fig. 7a1,a2). Furthermore, in control mice the mean time spent sniffing the first odor during the second exposure did not differ from the mean duration of investigating the second novel odor $\left(t_{13}=1.40 ; p>0.05\right)$, suggesting that for the animal, the previously encountered odor was as unfamiliar as the second odor. In other words, exposure to a distracting odor immediately after the presentation of a first one interfered with subsequent recognition of the later odor in standard mice. Interestingly, odor-enriched mice spent less time investigating odor 1 during the second presentation $\left(t_{13}=4.29 ; p<0.001\right)$ despite the exposure to odor 2 (Fig. $7 b 1, b 2$ ). The mean time spent investigating odor 1 during the initial exposure did not differ from the mean duration spent sniffing odor $2\left(t_{13}=0.87 ; p>0.05\right)$. These results indicate that enriched mice recognized the first odor and that the immediate presentation of a distractor did not interfere with the storage and the recall of the first odor memory.

\section{Olfactory enrichment does not affect the hippocampus}

After a 40 d period of olfactory enrichment, BrdU-labeled cells were found in the granular zone and in the hilus of the hippocampus (Fig. 8a,b). No difference in BrdU-positive cell density was observed between odor-enriched and standard group $\left(t_{10}=1.14 ; p>0.05\right)$ (Fig. $\left.8 c\right)$. Furthermore, to assess the potential consequences of odor-enriched environment on hippocampal-dependent memory, the ability of animals to find a hidden platform in the Morris water maze was tested. No difference in the performance of standard and odor-enriched mice could be found over the $4 \mathrm{~d}$ of place navigational learning (group, $\left.F_{(1,40)}=0.74 ; p>0.05\right)$. Both groups showed a significant reduction in the time needed to escape onto the platform over sessions (days, $F_{(3,120)}=56.49 ; p<0.001$ ) (Fig. 9a). The analysis did not reveal any significant interaction between the factors group and days $\left(F_{(3,120)}=1.14 ; p>0.05\right)$, suggesting that standard and odor-enriched mice learned to locate the platform to the same extent. As expected, during the probe trial, both groups did not explore the four quadrants homogeneously $\left(\mathrm{ANOVA}, F_{(3,36)}=42.36 ; p<0.001\right)$ and spent more time at the

$\leftarrow$

done $20 \mathrm{~d}$ after animals were assigned to their respective groups (day 0), and mice were killed $4 \mathrm{hr}$ after BrdU injection. $b$, Diagram of a parasagittal view showing the four sampling zones along a rostrocaudal axis. $c$, Schema representing the RMS, the lateral ventricle $(l v)$, the corpus callosum $(c c)$, and the striatum $(s t)$. Squares $(50 \times 50 \mu \mathrm{m})$ indicate three analyzed areas (ventral, lateral, and dorsal) for BrdU-IR cells in Zone II $+I I I$ of the lateral ventricle wall and one analyzed area both in the RMS and in Zone $I V$. $d$, Mean number of BrdU-IR cells per millimeters squared in each defined zone for standard and enriched mice. 
$a_{1}$

Standard

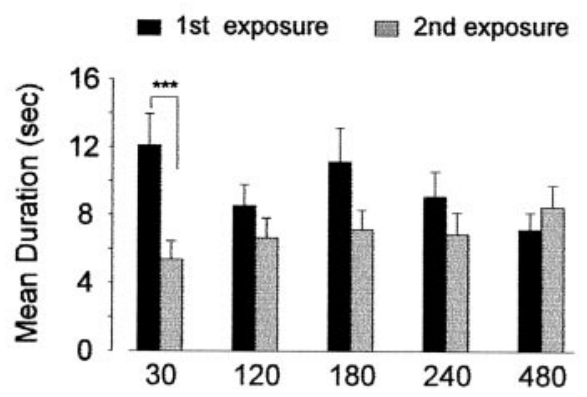

$a_{2}$

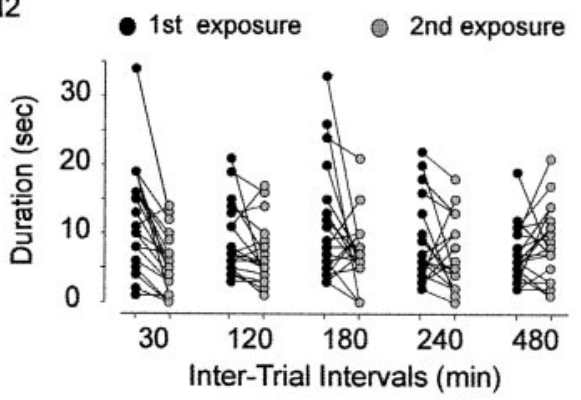

$a_{1}$

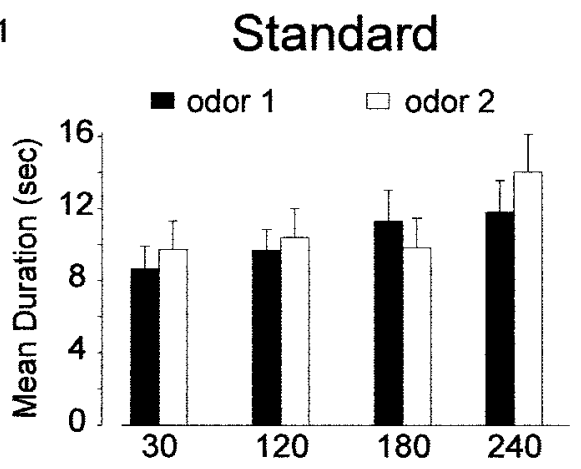

$a_{2}$

- odor 1

odor 2

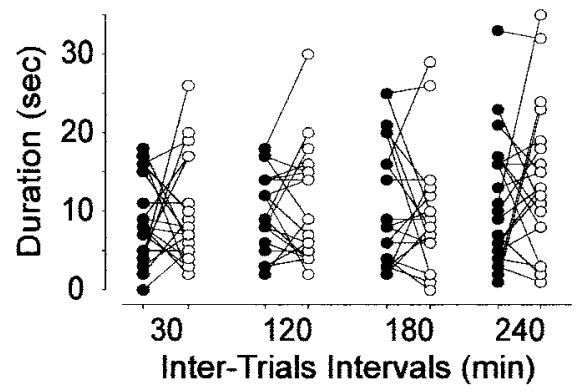

$b_{1}$

Enriched

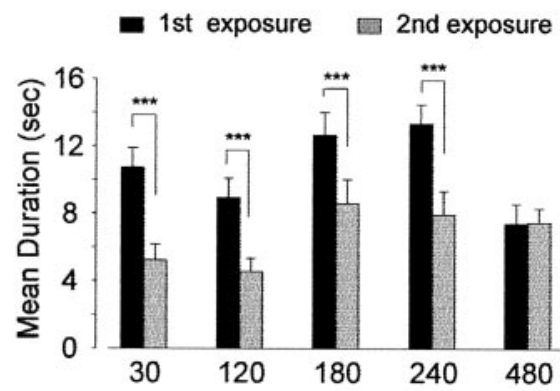

$b_{2}$

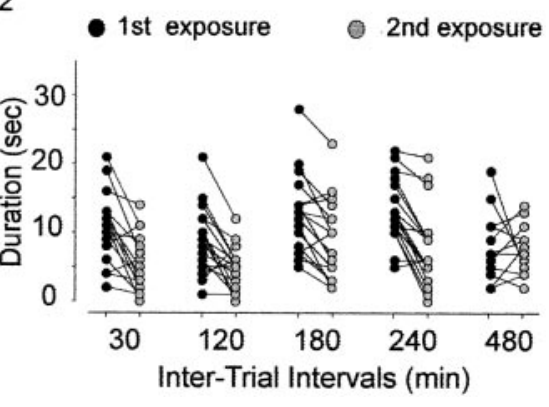

Figure 5. Enriched mice have longer olfactory memory. Effect of different intertrial intervals on odor recognition in standard $(n=19)$ and enriched $(n=17)$ mice. $a 1, b 1$, Each bar represents the mean time ( \pm SEM) spent investigating a given odor on the first exposure (black columns) and on the second exposure (gray columns). $a 2, b 2$, Time (in seconds) spent investigating odors by individual mice from the standard (a2) and enriched (b2) groups used in $a 1$ and $b 1 .{ }^{* *} p<0.001$ with a Student's $t$ test.

\section{b1 Enriched}

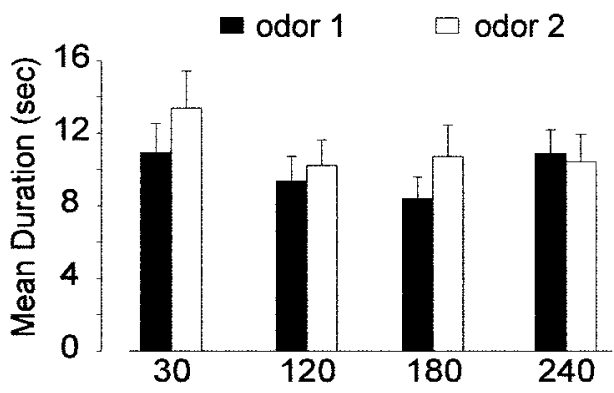

$b_{2}$ - odor 1

odor 2

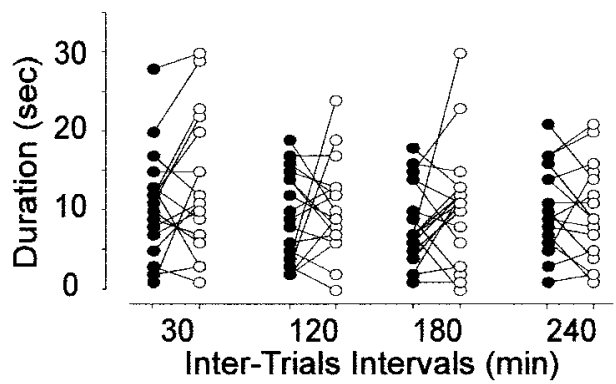

Figure 6. Specificity of the odor recognition in the short-term memory task. Effect of different intertrial intervals on time spent on new odor in standard $(n=$ $19)$ and enriched $(n=17)$ mice. $a 1, b 1$, Each bar represents the mean time ( \pm SEM) spent investigating a given odor on the first exposure (black columns, odor 1) and on the second exposure (white columns, odor 2). a2, b2, Detailed variations of each mouse spending time in the different intertrial intervals tested. expected target location (i.e., the training quadrant) than in others (Newman-Keuls post hoc analysis, $p<0.001$ ) (Fig. 9b). This clear bias for the target quadrant was statistically comparable in both groups (group $\times$ quadrants, $\left.F_{(3,36)}=1.33 ; p>0.05\right)$.

\section{DISCUSSION}

The present study was designed to investigate whether an enriched odor environment influences proliferation and survival of newborn olfactory interneurons in adult mice, and if so, whether subsequent changes in the bulbar neuronal network are associ- ated with olfactory memory. Our results show that despite a stable rate of proliferation in the RMS and the SVZ, the number of newborn neurons surviving in the main olfactory bulb was roughly doubled in mice exposed to an odor-enriched environment. This finding demonstrates that survival of newborn neurons can be specifically upregulated by odor exposure lasting $40 \mathrm{~d}$. Thus, cell proliferation and survival might be regulated independently. In agreement with this, enriched living affects only cell survival (Kempermann et al., 1997), whereas exercise increases both cell division and survival (van Praag et al., 1999) in the 


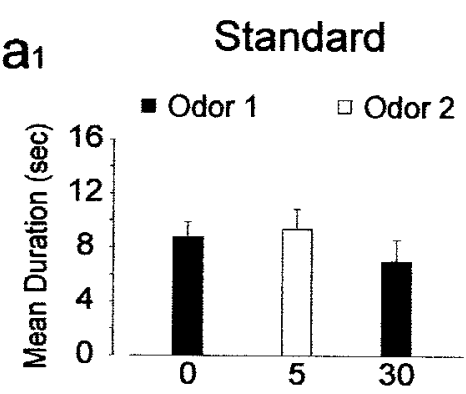

Figure 7. Odor recognition in enriched mice is not sensitive to a retroactive interference task. $a 1, b 1$, Effect of the presentation of a novel odor (white columns, odor 2) 5 min after the presentation of the first odor (dark columns, odor 1) on recognition. Each bar represents the mean time ( \pm SEM) spent investigating a given odor. Although standard mice $(n=14)$ were sensitive to this interference task, enriched mice $(n=14)$ could still recognize odor 1 after being exposed to odor 2. a2, $b 2$, Time (in seconds) spent investigating odors by individual mice from the standard and enriched groups displayed in a1 and $b 1 .{ }^{* * *} p<0.001$ with a Student's $t$ test.

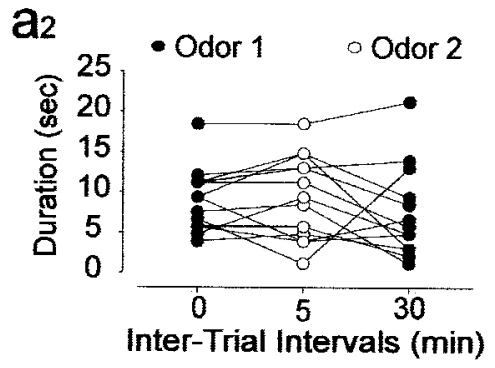

Standard
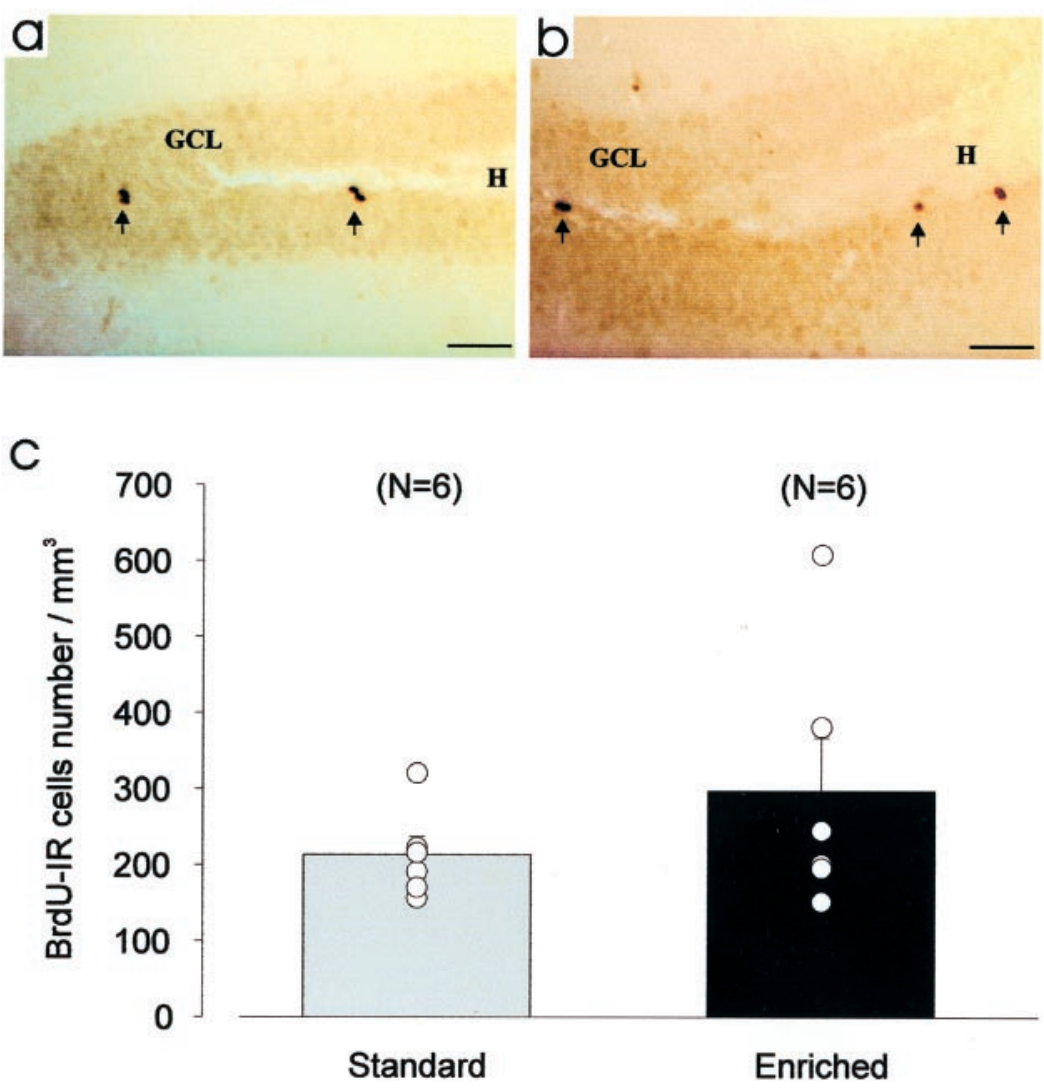

dendritic levels, as well as the release of factors mediated by bulbar activity, may participate to improve olfactory memory.

In the present study, we were also interested in investigating the effects of odor enrichment on hippocampal neurogenesis for three main reasons. First, similar relationships between morphological and behavioral changes have been reported recently in the

hippocampus after environmental enrichment (Rampon et al.,

Enriched

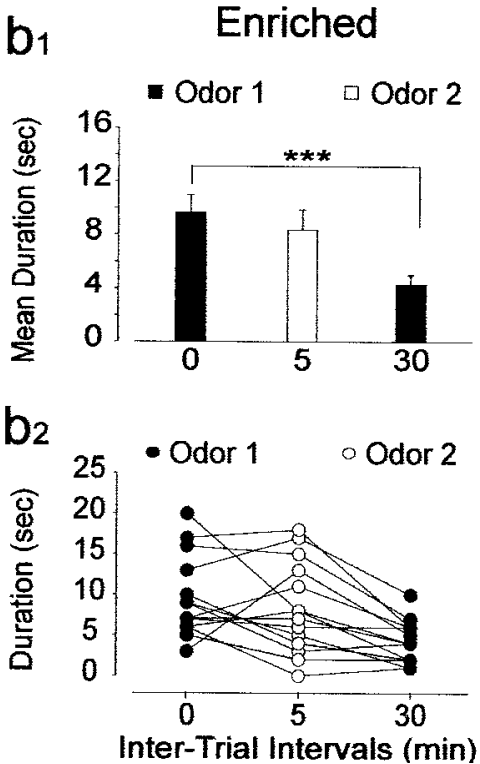

Olfactory enrichment has no effect on neurogenesis in the hippocampus. $a-b$, Light micrographs of BrdU-IR cells taken from coronal sections of hippocampus from standard $(a)$ and odor-enriched $(b)$ mice. To assess survival, animals received four injections of BrdU 3 weeks before not differ statistically between the two groups. $G C L$, Granule cell layer; $H$, hilus. Scale bar, $50 \mu \mathrm{m}$.

hippocampus. In the main olfactory bulb, the increase in the total number of newborn granule cells is accompanied by a longer and stronger (e.g., resistance to retroactive interference) olfactory memory. Although this result does not demonstrate a direct link between neurogenesis and behavioral performance, it is likely that a combination of an increase in the number of olfactory bulb interneurons and structural or functional changes at synaptic and 
a

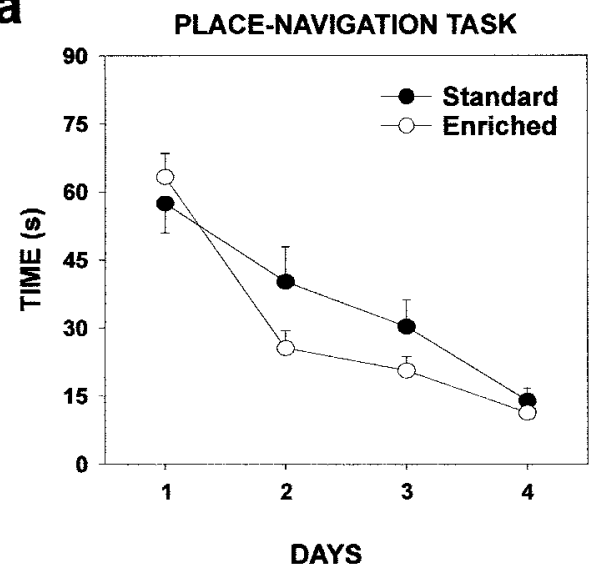

b

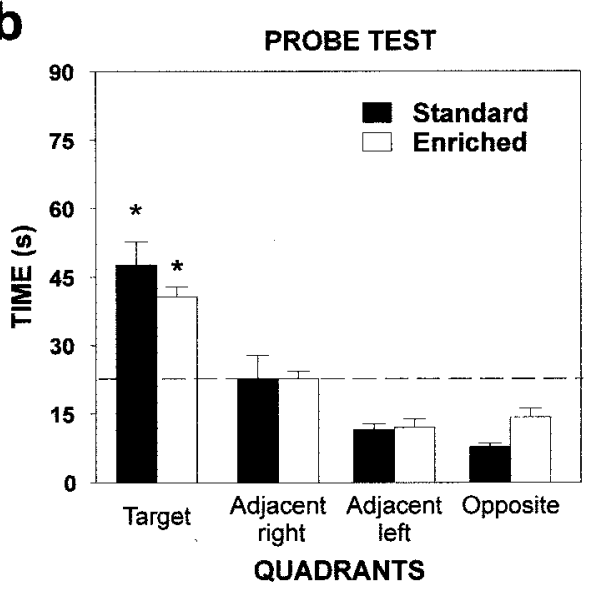

Figure 9. Olfactory enrichment does not improve spatial memory in the water maze task. $a$, Latency to climb onto the platform in a random starting version of the place navigation task (mean \pm SEM). Standard $(n=21)$ and odorenriched $(n=21)$ mice showed a similar reduction in escape latency over the $4 \mathrm{~d}$ of training. $b$, Mice from both groups spent significantly more time in the quadrant where the platform had been located during training than in the other quadrants $\left({ }^{*} p<0.001\right)$.
2000). Second, the main olfactory bulb sends projections to the hippocampus through the lateral entorhinal cortex. Finally, it has been well established that the hippocampus is involved in several olfactory memory tasks (Dusek and Eichenbaum, 1997; Wood et al., 1999). Our findings, however, did not reveal any difference in the density of newly generated neurons in the dentate gyrus between groups. Consistent with this result, enriched mice performed a place-navigation task (e.g., a task specifically involving the hippocampus) to the same extent as standard animals. These results demonstrate that structural changes after odor enrichment occurred in the main olfactory bulb and that only survival of neurons born in the SVZ, but not in the dentate gyrus, is enhanced under these conditions.

\section{Regulation of bulbar neurogenesis}

The present study suggests that ongoing neurogenesis is of fundamental biological significance because cell survival in the main olfactory bulb can be prolonged by sensory experience. This observation indicates that survival of new neurons is to some degree activity dependent. Previous studies have already reported that environmental complexity increases the number of adultgenerated neurons in birds and rodents, presumably by enhancing cell survival (Barnea and Nottebohm, 1994; Kempermann et al., 1997; Gould et al., 1999; van Praag et al., 1999) and facilitating the integration of adult-generated cells into the existing neural circuitry (Gould et al., 1999). In a study that complements our work, rat pups raised in an odor-enriched environment showed an increase in the number of olfactory bulb granule cells (RosselliAustin and Williams, 1990).

Previous works, using opposing manipulation that consisted of olfactory deprivation, showed results supporting our observations. In experiments based on reversible olfactory deprivation, a substantial increase in BrdU-labeled cells has been reported after naris reopening (Cummings et al., 1997). Furthermore, cell death in the main olfactory bulb has been studied using a reversible naris closure paradigm that showed enhanced apoptosis in the granule cell layer after occlusion, whereas opposite results were obtained after the occluded nares were reopened (Najbauer and Leon, 1995; Fiske and Brunjes, 2001). This indicates that cell survival seems to be subjected to a bidirectional modulation in response to the level of olfactory afferent activity. Similarly, the number of dying cells within the granule cell layer of odordeprived olfactory bulbs was significantly increased 4 weeks after unilateral naris closure (Corotto et al., 1994).
The mechanism linking the exposure to an odor-enriched environment and an increase in neuronal survival remains unknown. It may be that granule cells and their precursors require and compete for factors that are expressed to a higher degree in the odorenriched bulb. It is likely that precise temporal and spatial regulations of several factors are required for survival and differentiation of neuronal precursor cells. From both in vitro and in vivo studies, it is known that trophic factors can influence the fate of neural progenitor cells (Craig et al., 1996; Kuhn et al., 1997). Interestingly, it has been demonstrated that the maturation and survival of olfactory newly generated neurons are partly under the control of BDNF in vitro (Kirschenbaum and Goldman, 1995). Along this line, BDNF administrated intraventricularly was found to increase the number of newly generated neurons in the adult olfactory bulb (Zigova et al., 1998). However, data on experiencedependent modulation mediated by these factors are still lacking for the olfactory sensory system.

Previous studies have emphasized that neuronal progenitor cells are eliminated in the postnatal and adult SVZ and RMS (Morshead and van der Kooy, 1992; Brunjes and Armstrong, 1996; Levison et al., 2000). In line with this, some studies showed that most of the cells generated in the SVZ were eliminated after reaching the main olfactory bulb (Biebl et al., 2000). Our findings indicate that the increase of the population of newborn neurons resulted from a bulbar-dependent activity that promotes their survival, as opposed to the constitutive proliferation of granule cell precursors. The regulation of the production and survival of SVZ neuroblasts could change from a preprogrammed state during development to an activity-dependent state during adulthood.

\section{Sensory experience and inhibitory network}

Several types of behavior and perception such as human language, bird song, or binocular vision are shaped by sensory experience during a restricted "critical period" early in development, ceasing before or shortly after parturition (Berardi et al., 2000). During this critical period, sensory-driven activity patterns are able to induce long-term changes in specific neuronal circuits, thus causing functional remodeling that lasts throughout adulthood. Interestingly, trophic factors have been shown to regulate cortical plasticity by promoting the maturation of cortical inhibition (Huang et al., 1999). How might an increase in inhibition turn on the neuronal remodeling? First, inhibition may spatially or temporally filter sensory responses to create appropriate signals for recruiting plasticity mechanisms. A second possibility is that 
experience-dependent induced changes involve plasticity of inhibitory circuits. These possibilities suggest that high levels of inhibition may not be responsible for keeping neuronal plasticity closed, but instead the major role of inhibition in vivo may be to promote the onset of neuronal remodeling.

The large-scale production of immature inhibitory interneurons in the main olfactory bulb provides a substrate by which neural regulatory factors and olfactory bulb activity in the adult animal could direct the organization of developing neuronal inhibitory connections. Although the overall effects of enrichment seem to be beneficial, it is not clear how long these effects may last, nor what could happen when enrichment is discontinued. Previous studies showed that morphological and chemical changes within the brain are reversed when animals are removed from the enriched environment (Bennett et al., 1974; Green and Greenough, 1986). In contrast, we observed that mice that had lived in an enriched environment for $40 \mathrm{~d}$ and were then returned to standard housing still differed from controls in olfactory memory tests 2 months later (our unpublished data).

The main olfactory bulb is an important brain structure because it plays a central role in odor encoding and discrimination (for review, see Mori et al., 1999). Studies have provided evidence that, in addition to acquisition, the olfactory bulb has a transient role in memory and demonstrates a high degree of structural plasticity (Lynch and Granger, 1991). The relationships between bulbar neurogenesis and olfactory performance suggest a function for these new neurons in certain types of memory. In fact, the immature status of adult-generated bulbar interneurons makes them uniquely qualified to participate in the requisition and transient storage of information. Future experiments will be necessary to determine the mechanisms by which olfactory experience mediates greater survival of newly generated neurons in the main olfactory bulb. However, it is clear from the present study that changes in the environment of an adult animal and the ways that an individual animal reacts to those changes can have profound and robust effects on the brain and the behavior of that animal.

\section{REFERENCES}

Altman J, Das GD (1965) Autoradiographic and histological evidence of postnatal neurogenesis in rats. J Comp Neurol 124:319-335.

Barnea A, Nottebohm F (1994) Seasonal recruitment of hippocampal neurons in adult free-ranging black-capped chickadees. Proc Natl Acad Sci USA 91:11217-11221.

Bennett EL, Rosenzweig MR, Diamond MC, Morimoto H, Hebert M (1974) Effects of successive environments on brain measures. Physiol Behav 12:621-631.

Berardi N, Pizzorusso T, Maffei L (2000) Critical periods during sensory development. Curr Opin Neurobiol 10:138-145.

Biebl M, Cooper CM, Winkler J, Kuhn HG (2000) Analysis of neurogenesis and programmed cell death reveals a self-renewing capacity in the adult rat brain. Neurosci Lett 291:17-20.

Bluthé RM, Gheusi G, Dantzer R (1993) Gonadal steroids influence the involvement of arginine vasopressin in social recognition in mice. Psychoneuroendocrinology 18:323-351.

Bonfanti L, Theodosis DT (1994) Expression of polysialylated neural cell adhesion molecule by proliferating cells in the subependymal layer of the adult rat, in its rostral extension and in the olfactory bulb. Neuroscience 62:291-305.

Brunjes PC, Armstrong AM (1996) Apoptosis in the rostral migratory stream of the developing rat. Brain Res Dev 92:219-222.

Chazal G, Durbec P, Jankovski A, Rougon G, Cremer H (2000) Consequences of neural cell adhesion molecule deficiency on cell migration in the rostral migratory stream of the mouse. J Neurosci 20:1446-1457.

Conover JC, Doetsch F, Garcia-Verdugo JM, Gale NW, Yancopoulos GD, Alvarez-Buylla A (2000) Disruption of Eph/ephrin signaling affects migration and proliferation in the adult subventricular zone. Nat Neurosci 3:1091-1097.

Corotto FS, Henegar JR, Maruniak JA (1994) Odor deprivation leads to reduced neurogenesis and reduced neuronal survival in the olfactory bulb of the adult mouse. Neuroscience 61:739-744.

Craig CG, Tropepe V, Morshead CM, Reynolds BA, Weiss S, van der Kooy D (1996) In vivo growth factor expansion of endogenous subependymal neural precursor cell populations in the adult mouse brain. J Neurosci 16:2649-2658.

Cummings DM, Henning HE, Brunjes PC (1997) Olfactory bulb recovery after early sensory deprivation. J Neurosci 17:7433-7440.

Doetsch F, Alvarez-Buylla A (1996) Network of tangential pathways for neuronal migration in adult mammalian brain. Proc Natl Acad Sci USA 93:14895-14900.

Dusek JA, Eichenbaum H (1997) The hippocampus and memory for orderly stimulus relations. Proc Natl Acad Sci USA 94:7109-7114.

Fagiolini M, Hensch TK (2000) Inhibitory threshold for critical-period activation in primary visual cortex. Nature 404:183-186.

Fiske BK, Brunjes PC (2001) Cell death in the developing and sensorydeprived rat olfactory bulb. J Comp Neurol 431:311-319.

Gage FH (2000) Mammalian neural stem cells. Science 287:1433-1438.

Gould E, Beylin A, Tanapat P, Reeves AJ, Shors TJ (1999) Learning enhances adult neurogenesis in the hippocampal formation. Nat Neurosci 2:260-265.

Green EJ, Greenough WT (1986) Altered synaptic transmission in dentate gyrus of rats reared in complex environments: evidence from hippocampal slices maintained in vitro. J Neurophysiol 55:739-750.

Gross CG (2000) Neurogenesis in the adult brain: death of a dogma. Nat Rev Neurosci 1:67-73.

$\mathrm{Hu} \mathrm{H}$ (1999) Chemorepulsion of neuronal migration by Slit2 in the developing mammalian forebrain. Neuron 23:703-711.

Huang ZJ, Kirkwood A, Pizzorusso T, Porciatti V, Morales B, Bear MF, Maffei L, Tonegawa S (1999) BDNF regulates the maturation of inhibition and the critical period of plasticity in mouse visual cortex. Cell 98:739-755.

Jankovski A, Garcia C, Soriano E, Sotelo C (1998) Proliferation, migration and differentiation of neuronal progenitor cells in the adult mouse subventricular zone surgically separated from its olfactory bulb. Eur J Neurosci 10:3853-3868.

Kempermann G, Kuhn GH, Gage FH (1997) More hippocampal neurons in adult mice living in an enriched environment. Nature 386:493-495.

Kennedy TE, Tessier-Lavigne M (1995) Guidance and induction of branch formation in developing axons by target-derived diffusible factors. Curr Opin Neurobiol 5:83-90.

Kirschenbaum B, Goldman SA (1995) Brain-derived neurotrophic factor promotes the survival of neurons arising from the adult rat forebrain subependymal zone. Proc Natl Acad Sci USA 92:210-214.

Kirschenbaum B, Doetsch F, Lois C, Alvarez-Buylla A (1999) Adult subventricular zone neuronal precursors continue to proliferate and migrate in the absence of the olfactory bulb. J Neurosci 19:2171-2180.

Kuhn HG, Winkler J, Kempermann G, Thal LJ, Gage FH (1997) Epidermal growth factor and fibroblast growth factor-2 have different effects on neural progenitors in the adult rat brain. J Neurosci 17:5820-5829.

Levison SW, Rothstein RP, Brazel CY, Young GM, Albrecht PJ (2000) Selective apoptosis within the rat subependymal zone: a plausible mechanism for determining which lineages develop from neural cells. Dev Neurosci 22:106-115.

Lois C, Alvarez-Buylla A (1994) Long-distance neuronal migration in the adult mammalian brain. Science 264:1145-1148.

Lois C, Garcia-Verdugo JM, Alvarez-Buylla A (1996) Chain migration of neuronal precursors. Science 271:978-981.

Luskin MB (1993) Restricted proliferation and migration of postnatally generated neurons derived from the forebrain subventricular zone. Neuron 11:173-189.

Lynch G, Granger R (1991) Serial steps in memory processings: possible clues from studies of plasticity in the olfactory-hippocampal circuit. In: Olfaction, a model system for computational neuroscience (Davis JL, Eichenbaum H, eds), pp 141-165. Cambridge, MA: MIT.

Mori K, Nagao H, Yoshihara Y (1999) The olfactory bulb: coding and processing of odor molecule information. Science 286:711-715.

Morshead CM, van der Kooy D (1992) Postmitotic death is the fate of constitutively proliferating cells in the subependymal layer of the adult mouse brain. J Neurosci 12:249-256.

Mullen RJ, Buck CR, Smith AM (1992) NeuN, a neuronal specific nuclear protein in vertebrates. Development 116:201-211.

Murray RC, Calof AL (1999) Neuronal regeneration: lessons from the olfactory system. Semin Cell Dev Biol 10:421-431.

Najbauer J, Leon M (1995) Olfactory experience modulated apoptosis in the developing olfactory bulb. Brain Res 674:245-251.

Peretto P, Merighi A, Fasolo A, Bonfanti L (1999) The subependymal layer in rodents: a site of structural plasticity and cell migration in the adult mammalian brain. Brain Res Bull 49:221-243.

Rabin MD (1988) Experience facilitates olfactory quality discrimination. Percept Psychophys 44:532-540.

Rampon C, Tang YP, Goodhouse J, Shimizu E, Kyin M, Tsien JZ (2000) Enrichment induces structural changes and recovery from nonspatial 
memory deficits in CA1 NMDAR1-knockout mice. Nat Neurosci $3: 238-244$.

Rosselli-Austin L, Williams J (1990) Enriched neonatal odor exposure leads to increased numbers of olfactory bulb mitral and granule cells. Dev Brain Res 51:135-137.

Rousselot P, Lois C, Alvarez-Buylla A (1995) Embryonic (PSA) $\mathrm{N}-\mathrm{CAM}$ reveals chains of migrating neuroblasts between the lateral ventricle and the olfactory bulb of adult mice. J Comp Neurol 351:51-61.

Svendsen CN, Sofroniew MV (1996) Do central nervous system neurons require target-derived neurotrophic support for survival throughout adult life and aging? Perspect Dev Neurobiol 3:133-142.

Temple S, Alvarez-Buylla A (1999) Stem cells in the adult mammalian central nervous system. Curr Opin Neurobiol 9:135-141. van Praag H, Kempermann G, Gage FH (1999) Running increases cell proliferation and neurogenesis in the adult mouse dentate gyrus. Nat Neurosci 2:266-270.

Woo CC, Leon M (1995) Early olfactory enrichment and deprivation both decrease beta-adrenergic receptor density in the main olfactory bulb of the rat. J Comp Neurol 360:634-642.

Wood ER, Dudchenko PA, Eichenbaum H (1999) The global record of memory in hippocampal neuronal activity. Nature 397:613-616.

Wu W, Wong K, Chen J, Jiang Z, Dupuis S, Wu JY, Rao Y (1999) Directional guidance of neuronal migration in the olfactory system by the protein Slit. Nature 400:331-336.

Zigova T, Pencea V, Wiegand SJ, Luskin MB (1998) Intraventricular administration of BDNF increases the number of newly generated neurons in the adult olfactory bulb. Mol Cell Neurosci 11:234-245. 